\title{
The effect of auditory distractors on song discrimination in male canaries (Serinus canaria)
}

\author{
Didier Appeltants ${ }^{\mathrm{a}}$, Timothy Q. Gentner ${ }^{\mathrm{b}, 1}$, Stewart H. Hulse ${ }^{\mathrm{b}}$, \\ Jacques Balthazart ${ }^{\mathrm{a}, *}$, Gregory F. Ball ${ }^{\mathrm{b}}$ \\ a Department of Cellular and Molecular Neurobiology, Research Group in Behavioral Neuroendocrinology, University of Liège, \\ 17 Place Delcour (Bat. L1), B-4020 Liège, Belgium \\ ${ }^{\mathrm{b}}$ Department of Psychological and Brain Sciences, Johns Hopkins University, Baltimore, MD 21218, USA
}

Received 16 May 2004; received in revised form 20 January 2005; accepted 20 January 2005

\begin{abstract}
Male songbirds such as canaries produce complex learned vocalizations that are used in the context of mate attraction and territory defense. Successful mate attraction or territorial defense requires that a bird be able to recognize individuals based on their vocal performance and identify these songs in a noisy background. In order to learn more about how birds are able to solve this problem, we investigated, with a two-alternative choice procedure, the ability of adult male canaries to discriminate between conspecific song segments from two different birds and to maintain this discrimination when conspecific songs are superimposed with a variety of distractors. The results indicate that male canaries have the ability to discriminate, with a high level of accuracy song segments produced by two different conspecific birds. Song discrimination was partially maintained when the stimuli were masked by auditory distractors, but the accuracy of the discrimination progressively declined as a function of the number of masking distractors. The type of distractor used in the experiments (other conspecific songs or different types of artificial white noise) did not markedly affect the rate of deterioration of the song discrimination. These data indicate that adult male canaries have the perceptual abilities to discriminate and selectively attend to one ongoing sound that occurs simultaneously with one or more other sounds. The administration of a noradrenergic neurotoxin did not impair markedly the discrimination learning abilities although the number of subjects tested was too small to allow any firm conclusion. In these conditions, however, the noradrenergic lesion significantly increased the number failures to respond in the discrimination learning task suggesting a role, in canaries, of the noradrenergic system in some attentional processes underlying song learning and processing.
\end{abstract}

(c) 2005 Elsevier B.V. All rights reserved.

Keywords: Song discrimination; Auditory scene analysis; Canary; Songbirds; Noradrenergic system

\footnotetext{
* Corresponding author. Tel.: +3243665970; fax: +3243665971.

E-mail address: jbalthazart@ulg.ac.be (J. Balthazart).

${ }^{1}$ Present address: Department of Psychology, University of California, San Diego, La Jolla, CA 92093, USA.
}

\section{Introduction}

Birdsongs are complex acoustic signals transmitted across generations via learning (reviewed by Marler, 1997; Ball and Hulse, 1998). Several lines of evi- 
dence demonstrate the importance of hearing for song learning. During a sensory phase of song acquisition, nestlings must hear conspecific vocalizations to form an auditory memory that will later guide song production during the sensorimotor phase of song development (Marler, 1997). The ability to process correctly song auditory information continues to be important in adulthood, in order to maintain normal song activity (Leonardo and Konishi, 1999) as well as to manage conspecific social interactions. Birdsong most often functions in a social context either to repel competing males from a territory or to attract females for mating (Peter et al., 1980; Kroodsma and Byers, 1991; Lind et al., 1996; Eens, 1997). It is, therefore, important that birdsong be processed acoustically by both male and female songbirds if they are to survive and reproduce. Songbirds must, therefore, be able to discriminate, recognize and pay specific attention to important conspecific signals and ignore the irrelevant auditory features inherent to the rich acoustic environment in which song is usually produced.

These higher-level capacities to process sounds as complex signals have been relatively little studied in songbirds under controlled laboratory conditions. Operant conditioning procedures have been successfully applied to the study of auditory perception in European starlings, Sturnus vulgaris. These studies have demonstrated that this wild songbird species is able to discriminate and identify the songs of several species (starling, brown thrasher, mockingbird and nightingale) presented concurrently with one another (Hulse et al., 1997) and to discriminate between the songs of two conspecifics when additional songs from other starlings are superimposed to partially mask the target signals (Wisnieski and Hulse, 1997). These results indicate that European starlings have the ability to discriminate and selectively attend to one ongoing sound that occurs simultaneously with one or more other sounds. This ability refers to the auditory scene analysis (Bregman, 1990) and can be illustrated by the "cocktail party effect", in which one identifies one speech source among a mixture of other speech sources (e.g. Wood and Cowan, 1985). Until now, these abilities have not been studied in other bird species (see Hulse, 2002).

In the present study, a two-alternative choice procedure was used to investigate cognitive abilities associated with the auditory processing of song infor- mation in a domesticated songbird species, the canary (Serinus canaria). The ability of adult male canaries to discriminate song segments from two different canaries and to learn arbitrary associations between these songs and two different locations in an operant apparatus were first investigated with a discrimination learning task. Once the birds exhibited a high level of correct responses, they were placed in a second experimental paradigm designed to investigate their ability to identify correctly the target song when it was partially masked by other conspecific songs or by white noise. In this behavioral task, canaries must use selective attentional functions to identify the stimuli despite the addition of acoustic interference.

In passerines, the ability to learn, produce and perceive complex vocalizations has evolved in association with a neural specialization, the song control system, that consists of a network of interconnected brain nuclei (Nottebohm et al., 1976; reviewed by Brenowitz et al., 1997; Ball and Hulse, 1998; Zeigler and Marler, 2004). In male canaries, the telencephalic parts of this specialization receive a strong and specific catecholaminergic innervation arising partly from the locus coeruleus (Appeltants et al., 2000, 2001, 2002a). High densities of $\alpha_{2}$-noradrenergic receptors have also been demonstrated in several song nuclei (Ball, 1994; Riters et al., 2002). Similarly, several relays in the auditory pathway connecting the auditory hair cells to the song control system receive a dense catecholaminergic innervation. This is particularly the case for the caudo-medial nidopallium (NCM, formerly caudo-medial neostriatum; see Reiner et al., 2004 for the revised avian neuroanatomical nomenclature). Although the exact functions of these catecholaminergic inputs are still not well understood, the noradrenergic system has been shown to be important for attention and vigilance in other species (Aston-Jones et al., 1994) and norepinephrine increases the signal to noise ratio of postsynaptic responses (Sara, 1985; Woodward et al., 1991). In addition, $\alpha_{2}$-noradrenergic receptors have been proposed to be involved in auditory processing in humans (Turetsky and Fein, 2002). In the present study, one group of birds was, therefore, systemically treated with a noradrenergic neurotoxin in order to investigate the potential role of the noradrenergic innervation of the brain in attention, auditory perception and discrimination. 


\section{Material and methods}

Adult male canaries were first shaped to obtain food by sitting on perches in an operant conditioning apparatus. The birds were then treated systemically either with a noradrenergic neurotoxin (see below for more detail), or with the vehicle before being trained in an alternative choice discrimination task to distinguish between five song segments of a male canary (A) and five other song segments produced by another male canary (B). When birds were able to discriminate the two sets of song segments accurately, we tested their ability to maintain the discrimination with different kinds of distractors superimposed on the target song.

\subsection{Subjects}

This study was performed on adult male canaries (American singer breed; $n=7$ ) purchased from a local breeder near Baltimore (Murad Breeders, Severna Park, MD). Before the beginning of the experiment, the birds were maintained in indoor aviaries in groups of six to eight birds per cage under a photoperiod of $11 \mathrm{~h}$ of light and $13 \mathrm{~h}$ of dark per day, with food and water available ad libitum. The aviary contained other canaries and European starlings. Three birds received an intramuscular injection of DSP-4 or $\mathrm{N}$-(2-chloroethyl)- $\mathrm{N}$-ethyl2-bromobenzylamine hydrochloride, a potent and selective neurotoxin of noradrenergic neurons (Lyons et al., 1989). DSP-4 specifically destroys noradrenergic axons via the reuptake pathway and is specific to locus coeruleus (LC) projecting neurons (Fritschy and Grzanna, 1991). DSP-4 when administered systemically significantly depletes norepinephrine (but not dopamine) in song nuclei (e.g. about $40 \%$ depletion in area X) of zebra finch brains (Barclay et al., 1991) and in the locus coeruleus in rat brains (Fritschy and Grzanna, 1992). Systemic injections of DSP-4 cause only transient damage to peripheral noradrenergic neurons whereas the effect on central norepinephrine innervation is long lasting (Hallman et al., 1984; JaimEtcheverry and Zieher, 1980). Three birds were treated with $0.05 \mathrm{ml} \mathrm{DSP}-4(100 \mathrm{mg} / \mathrm{kg}$ dissolved in saline solution) and four birds received a control injection of saline $(\mathrm{NaCl}, 0.9 \% ; 0.05 \mathrm{ml})$. This dose of DSP-4 significantly and specifically depletes norepinephrine levels in the telencephalon of zebra finches and other avian and mammalian species (Barclay et al., 1991, 1996; Balthazart et al., 1988; Fritschy and Grzanna, 1989; Lyons et al., 1989). The drug was placed in solution immediately prior to administration and males were randomly assigned to the control and experimental groups. Each bird was trained on the basic discrimination task. Each of these birds was run through the basic discrimination task but only two of DSP-4 treated birds and three controls were then tested through the second condition that required discrimination of songs from canary A and canary B mixed with superimposed auditory distractors.

\subsection{Apparatus}

During experimental sessions, each canary was tested in an operant test cage mounted inside a sound attenuation chamber (see Fig. 1A). This operant apparatus was equipped with a light, a speaker, two lateral perches in close proximity to food dispensers, a central observation perch and infrared detectors associated with each perch. A computer controlled stimulus presentations, response reinforcement contingencies and data collection.

\subsection{Stimuli}

We recorded the songs of eight adult male canaries (randomly outbred from heterogeneous genetic stocks, usually referred to as Belgian singers or Malines breed) in Liege, Belgium, with a Sony TCM-5000EV tape deck, and then transferred the recordings to digital format at a sampling rate of $22,050 \mathrm{~Hz}, 16 \mathrm{bit}$. From these songs, we chose five samples of approximately $15 \mathrm{~s}$ duration within songs of longer duration (randomly selected strophes within songs longer than $15 \mathrm{~s}$ ) from two arbitrarily selected birds. The five song samples from each of these birds, referred to as 'Canary-A' and 'Canary-B', served as the two sets of training stimuli for the initial discrimination, and as the target stimuli during subsequent testing (Fig. 1B).

We also selected four $15 \mathrm{~s}$ samples of continuous song from the remaining six males and these samples were used as distractive test-stimuli in parallel with eight types of artificial white noise. In each type of test-stimulus, one to six songs or white noises of varying intensity were combined with one of the 10 target stimuli (see Table 1). 
(A)

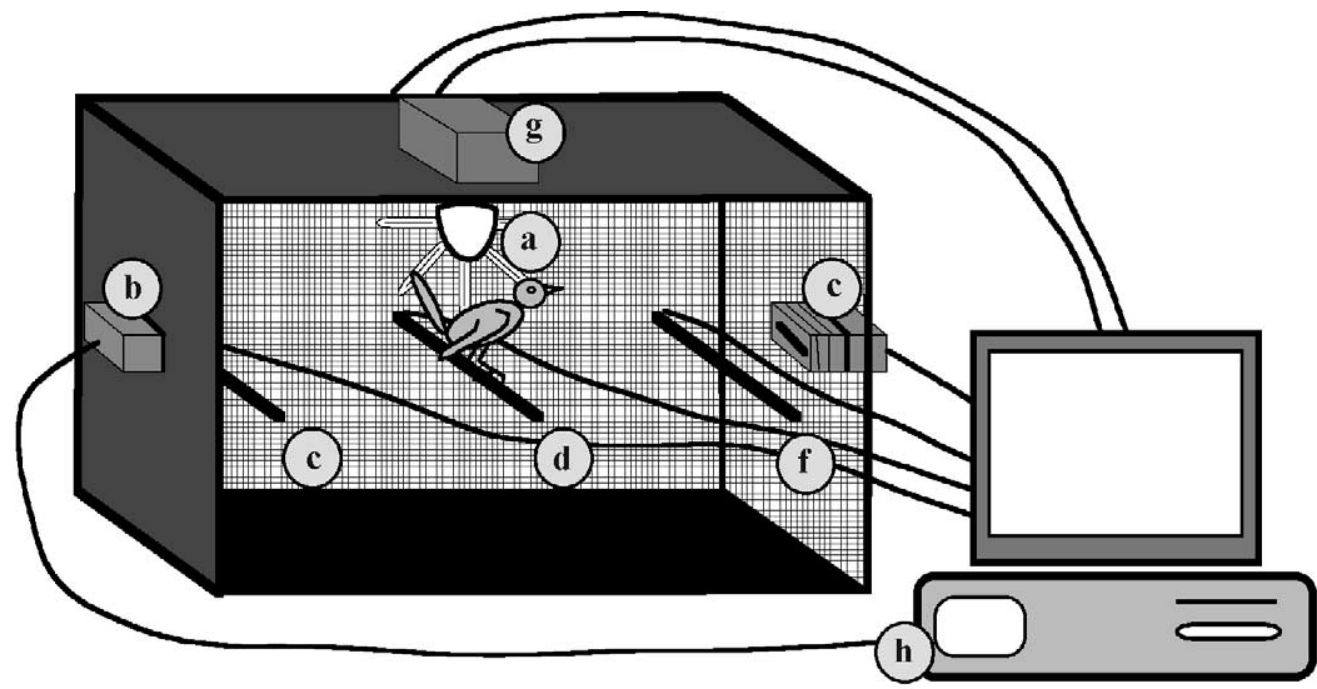

(B)
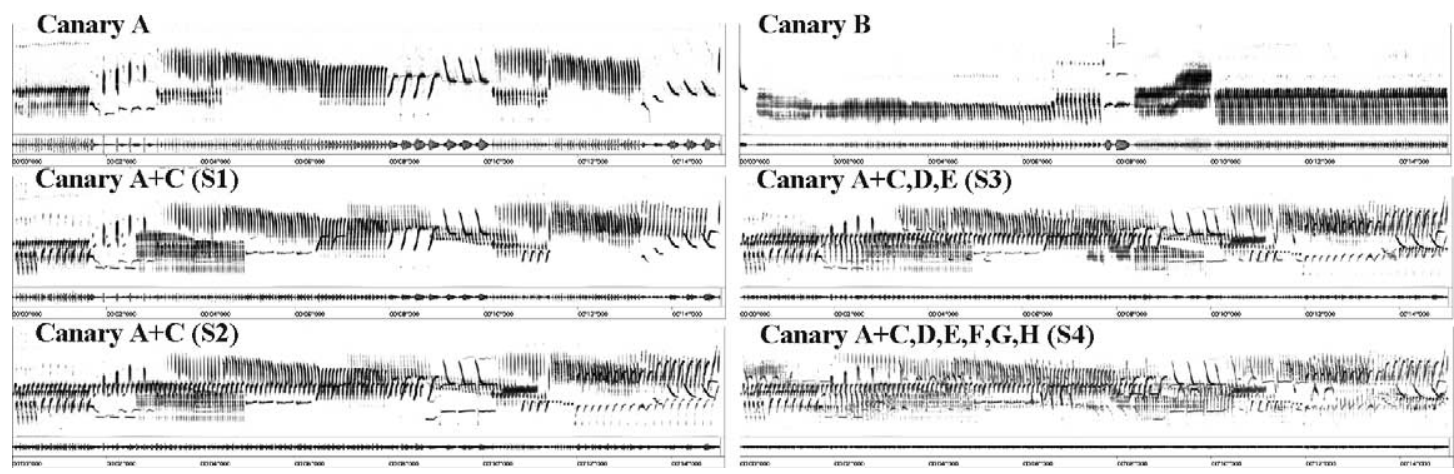

Fig. 1. (A) Schematic illustration of the operant apparatus used to investigate the auditory abilities of adult male canary. During experimental sessions, each canary was tested in an operant test cage mounted inside a sound attenuation chamber (not represented). A light (a) provided illumination and behavior could be observed through a small glass window (not represented). The right and left lateral walls of the test cages contained a food dispenser ( $b$ and $c$ ). An observation perch (d) was placed in the middle of the cage and two response perches (e and $f$ ) were placed in front of each food dispenser. Each perch was equipped with infrared detectors and a speaker (g) was placed above the central perch. Stimulus, responses and reinforcement contingencies were controlled on line by a PC-type computer (h) that also recorded data. (B) Sonograms illustrating examples of the stimuli used in the discrimination tests. Two examples of the target songs from canary "A" and "B" are shown on the top row as well as sonograms of stimuli composed of one song from canary "A" on which one, two, three or six additional songs were superimposed (combinations S1-S4; see text and Table 1 for additional explanations).

For the 'S1' test-stimuli (target + one song), we combined one of four songs from a third canary ('Canary-C') selected at random, with each of the 10 target songs from canaries A and B, yielding 40 different S1 stimuli (see Table 1). For the 'S2' test-stimuli (target + two songs), we combined each S1 stimulus with one of four songs from a fourth canary ('CanaryD'), which was again selected at random from the remaining recorded birds. The 'S3' test-stimuli (tar- get + three songs) were created by combining one of four songs from Canary-E to the each of the S3 stimuli (see Table 1). Finally for the 'S4' test-stimuli (target + six songs), we combined one of four songs from three remaining canaries $(\mathrm{F}-\mathrm{H})$ to each of the $\mathrm{S} 3 \mathrm{stim}-$ uli (see Table 1).

Note that we did not exhaustively test the complete stimulus space comprising all possible permutations of target and distractive song stimuli. The songs from a 
Table 1

Stimulus configuration patterns for all the test-stimuli used this experiment

\begin{tabular}{|c|c|c|c|}
\hline Condition & Target & Distractor & Stimulus \\
\hline Baseline & $\mathrm{A}, \mathrm{B}$ & - & $\mathrm{A}, \mathrm{B}$ \\
\hline S1 & $\mathrm{A}, \mathrm{B}$ & $\mathrm{C}$ & $\mathrm{A}+\mathrm{C}, \mathrm{B}+\mathrm{C}$ \\
\hline $\mathrm{S} 2$ & $\mathrm{~A}, \mathrm{~B}$ & C, D & $\mathrm{A}+\mathrm{C}+\mathrm{D}, \mathrm{B}+\mathrm{C}+\mathrm{D}$ \\
\hline S3 & $\mathrm{A}, \mathrm{B}$ & $\mathrm{C}, \mathrm{D}, \mathrm{E}$ & $\mathrm{A}+\mathrm{C}+\mathrm{D}+\mathrm{E}, \mathrm{B}+\mathrm{C}+\mathrm{D}+\mathrm{E}$ \\
\hline S4 & A, B & C, D, E, F, G, H & $\begin{array}{l}A+C+D+E+F+G+H \\
B+C+D+E+F+G+H\end{array}$ \\
\hline WN1 & $\mathrm{A}, \mathrm{B}$ & $\mathrm{N}_{\mathrm{C}}$ & $A+N_{C}, B+N_{C}$ \\
\hline WN2 & $\mathrm{A}, \mathrm{B}$ & $\mathrm{N}_{\mathrm{C}}, \mathrm{N}_{\mathrm{D}}$ & $A+N_{C}+N_{D}, B+N_{C}+N_{D}$ \\
\hline WN3 & A, B & $\mathrm{N}_{\mathrm{C}}, \mathrm{N}_{\mathrm{D}}, \mathrm{N}_{\mathrm{E}}$ & $A+N_{C}+N_{D}+N_{E}, B+N_{C}+N_{D}+N_{E}$ \\
\hline WN4 & A, B & $\mathrm{N}_{\mathrm{C}}, \mathrm{N}_{\mathrm{D}}, \mathrm{N}_{\mathrm{E}}, \mathrm{N}_{\mathrm{F}}, \mathrm{N}_{\mathrm{G}}, \mathrm{N}_{\mathrm{H}}$ & $\begin{array}{l}A+N_{C}+N_{D}+N_{E}+N_{F}+N_{G}+N_{H} \\
B+N_{C}+N_{D}+N_{E}+N_{F}+N_{G}+N_{H}\end{array}$ \\
\hline WN5 & $\mathrm{A}, \mathrm{B}$ & White noise @ $-15 \mathrm{~dB}$ re target & $\mathrm{A}+$ noise, $\mathrm{B}+$ noise \\
\hline WN6 & $\mathrm{A}, \mathrm{B}$ & White noise @ $-10 \mathrm{~dB}$ re target & $\mathrm{A}+$ noise, $\mathrm{B}+$ noise \\
\hline WN7 & $\mathrm{A}, \mathrm{B}$ & White noise @ -5 dB re target & $\mathrm{A}+$ noise, $\mathrm{B}+$ noise \\
\hline WN8 & $\mathrm{A}, \mathrm{B}$ & White noise @ $0 \mathrm{~dB}$ re target & $\mathrm{A}+$ noise, $\mathrm{B}+$ noise \\
\hline
\end{tabular}

Different letters $(A-G)$ denote songs from different birds; plus signs denote linear composition of waveforms. See text for descriptions of the specific stimuli within each condition.

given bird are denoted by numbers (e.g. C1, C2, C3, C4, for the four songs from canary $\mathrm{C}$ ) and the songs combined as the distractive stimulus always shared the same number. For example, the combinations 'A $1+\mathrm{C} 4+\mathrm{D} 4$ ' and ' $\mathrm{B} 1+\mathrm{C} 1+\mathrm{D} 1+\mathrm{E} 1$ ' were included in the $\mathrm{S} 2$ and $\mathrm{S} 3$ conditions, respectively, whereas 'A $1+\mathrm{C} 2+\mathrm{D} 4$ ' and ' $\mathrm{B} 4+\mathrm{C} 4+\mathrm{D} 2+\mathrm{E} 3$ ' were not included. Thus, there were four different distractive song stimuli within each condition (16 total), and therefore, 40 test-stimuli in each separate condition S2 through S4. Prior to combination, each song sample was normalized such that the peak amplitude in all waveforms were equivalent, and $10 \mathrm{~ms}$ linear onset and offset ramps were added. The target and distractive stimulus waveforms were combined additively (in the digital domain) with equal weights and the resulting waveform scaled to the maximum dynamic range. Each of the 40 different teststimuli was constructed in this manner from its respective single song components.

In addition to the 'target + song' test-stimuli, we created 16 distractive stimuli using white noise. For each noise stimulus, the mean root mean square (RMS) amplitude equaled the mean RMS for one of the 24 individual distractive song stimuli (C1-4, D1-4, E1-4, F1-4, G1-4, and H1-4). We then combined those stimuli following the patterns for the target + song test-stimuli described above (see Table 1). Finally, we also used four other intensities of white noise in a single waveform
$(-15 \mathrm{~dB},-10 \mathrm{~dB},-5 \mathrm{~dB}$, and $0 \mathrm{~dB}$ below the average intensity of the canary song stimulus) to mask the target songs, respectively, WN5-WN8.

\subsection{Procedure}

Each canary was tested in the experimental apparatus twice per day for $3 \mathrm{~h}$ at a time, once from 08:50 to 11:50 a.m. and once from 02:50 to 05:50 p.m., 7 days per week. When the birds were not participating in the experiment, they were housed individually with ad libitum access to water. Food was usually delivered only in the experimental apparatus but animals were weighed before and after each session and ensure adequate feeding, supplemental food was provided if necessary. The behavioral procedure was composed of three successive conditions; shaping, baseline discrimination training, and testing with auditory distractor stimuli. The duration of the experiment was defined by the performance of the subjects not in terms of days to reach the present criteria. The entire experiment thus lasted a maximum of 3 weeks but birds that learned the discrimination task rapidly complete the entire protocol in a shorter period (less than a week for the fastest subjects).

\subsection{Acquisition of the discrimination procedure}

During the shaping condition, experimentally naive birds were progressively trained to sit on the perches to 
have access to food. First, the bird had to sit on the central perch to have access to one of the two feeders. After at least 200 trials, when this response was acquired, the bird had to sit, in a second phase, first on the central perch and after on the right or left perch to have access to one of the two feeders. This shaping condition was completed in 2-3 days.

Birds were then placed in the discrimination learning condition. During baseline training, the canaries were trained to discriminate between five song segments of two different canaries. Each set of songs (canary A songs or canary B songs) was associated to one of the two lateral perches and each stimulus was presented with the same probability $(p=0.5)$. Subjects initiated a trial by sitting on the central perch. In response to this behavior, one of the stimuli A or B was played through the speaker above the central perch. Sitting on any perch during the first $5 \mathrm{~s}$ of the stimulus presentation (no response time) had no consequences. After this observation period, sitting on the correct perch stopped the stimulus and generated a $1 \mathrm{~s}$ access to food (feedtime) from the feeder. If the bird sat on the wrong perch, the stimulus stopped and the house lights were turned off for $5 \mathrm{~s}$ (time out). The same stimulus was then used for the next trial (correction trial). Failures to respond were always followed by correction trials. Once the birds were responding to a criterion of $90 \%$ accuracy for five blocks of 100 trials, the rate of reinforcement for correct responses was lowered from $100 \%$ to $70 \%$. When the performance of the bird reached again the criterion of $90 \%$ accuracy, this bird was introduced in the next condition.

\subsection{Discrimination in the presence of distractors}

During this second condition the ability of the birds to maintain the correct discrimination of songs from canary A and canary B were assessed when these stimuli were mixed with superimposed conspecifics songs or white noises. In this condition, presentation of song segments from canary A and canary $\mathrm{B}$ was randomized, and the presentation of the canary A and canary B stimuli alone took place during $25 \%$ of the trials for each. The remaining of the trials $(50 \%$ of the total) contained equal numbers of presentation of all conditions with distractors (S1-S4, WN1-WN4 and WN5-WN8). These 12 types of dis- tractors were presented in random order at equal frequencies. The procedure was identical to the one used in the discrimination learning task except that the rate of reinforcement for correct responses was fixed at $70 \%$. The experiments stopped when each bird had responded to at least 50 trials of each condition (stimuli + one song, stimuli + one white noise, stimuli + two songs, stimuli + two white noise, stimuli + three songs, ...).

\section{Results}

\subsection{Acquisition phase}

Data were collected during this experimental phase on a total number of seven birds that were tested through the different tasks (saline, $n=4$; DSP-4, $n=3$ ). Birds of both groups progressively learned the discrimination and reached a high level of correct responses (>90\% accuracy) after a variable number of trial blocks (200 trials per block) ranging between 15 and 54. This demonstrated that male canaries have the perceptual ability to discriminate correctly between conspecific song segments. These data were analyzed by a twoway analysis of variance (ANOVA) with one independent variable (saline and DSP-4 groups) and one repeated variable (first 15 blocks of 200 learning trials, i.e. the only period during which data are available for all subjects; training was discontinued after 15 blocks if subjects had learned the procedure). As illustrated in Fig. 2, there was a slight tendency for the saline group to learn the discrimination faster but this difference was not significant (ANOVA: $F_{1,5}=0.509$, NS). The analysis indicated, however, a clearly significant effect of the repeated testing (ANOVA: $F_{14,70}=9.597$, $p=0.0001$ ) confirming that the birds efficiently learned the discrimination in subsequent trials. There was no significant interaction between repeated testing and groups (ANOVA: $F_{14,70}=0.571$, NS). Indicating that both groups learned at roughly equivalent rates.

The percentage of correct or incorrect responses and of trials where no response was produced (no resp.) was also calculated for both groups over the course of learning (see Fig. 3). Similar numbers of correct and incorrect responses were observed in the two groups of subjects but the absence of responding was observed more 


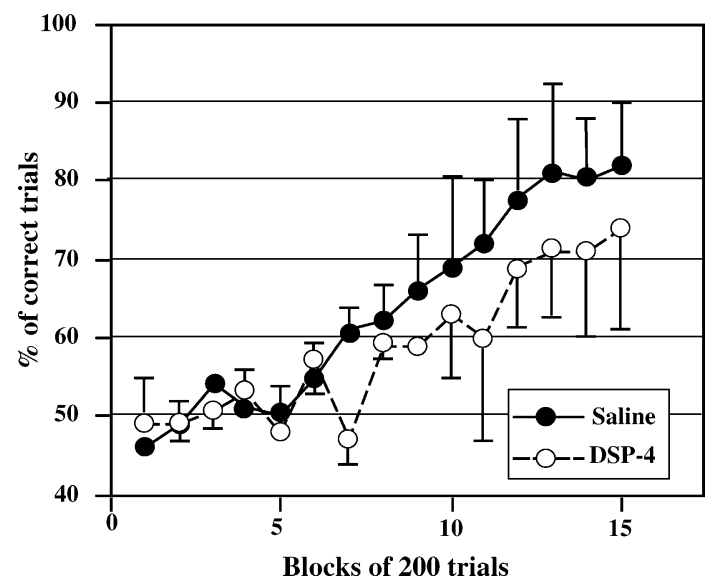

Fig. 2. Mean ( \pm S.E. $)$ percentage of correct trials in the discrimination between the song segments from canary A and canary B. These data represent the acquisition of the discrimination during the 15 first blocks of 200 trials. Some subjects did not reach the criterion within 15 blocks and were thus trained for a longer period (not illustrated here).

frequently in DSP-4 treated males. These data were analyzed by two-tailed $t$-tests for independent samples. These analyses confirmed the presence of a significant difference in the mean number and percentage of absence of response between the two groups $(t=3.392$, $p<0.05$ and $t=2.846, p<0.05$, respectively). There was, however, no difference between saline- and DSP4-treated birds in the mean number and percentage of correct ( $t=0.189$, NS and $t=2.309$, NS, respectively) or incorrect responses $(t=0.13$, NS and $t=2.179$, NS, respectively).

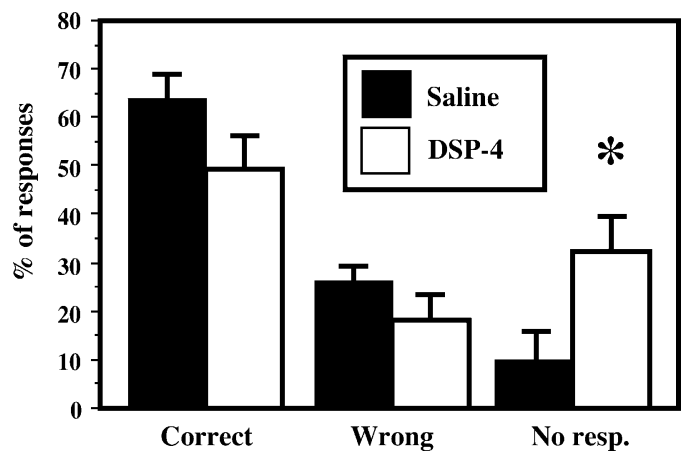

Fig. 3. Mean ( \pm S.E.) percentage of correct, wrong and no responses during all trials (no-correction and correction tests) to reach the learning criterion during the discrimination learning task (unpaired $t$-test: $\left.{ }^{*} p<0.05\right)$.

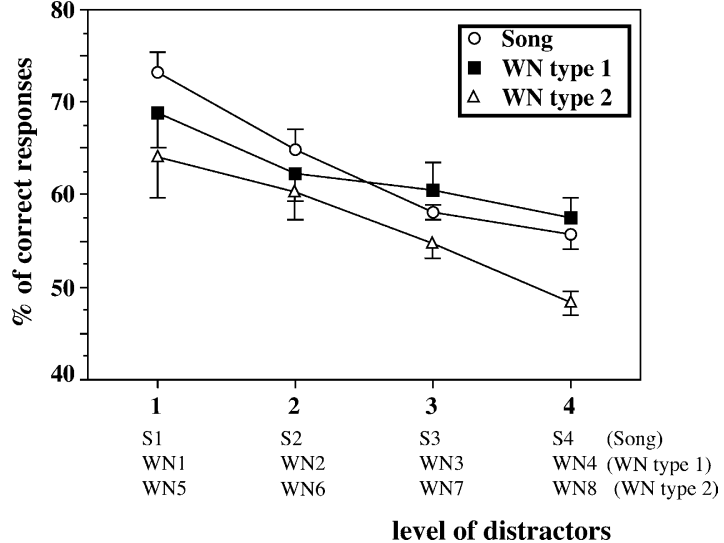

Fig. 4. Mean ( \pm S.E. $)$ percentage of correct responses in the discrimination of song segments from canary A and canary B mixed with superimposed conspecific song segments (S1-S4), white noise segments whose average intensities was the same as the conspecific song segments (WN1-WN4) and white noise segments with increased average intensity (WN5-WN8).

\subsection{Discrimination in the presence of distractive stimuli}

The bird's ability to maintain the discrimination when the stimuli were superimposed with different numbers or types of distractors is illustrated in Fig. 4. The quality of the discrimination between the two types of canary songs was largely maintained when a small number of distractors or a distractor of low intensity was used. However, the discrimination progressively decreased as a function of the number or intensity of the distractors added to the stimuli. There was no obvious difference related to the type of distractors that were used. The two groups of subjects also appeared to react in a similar manner to these tests.

These data were first analyzed by a three-way ANOVA with one independent factor (two groups) and two repeated factors: the type of distractors (three levels: song, WN whose average intensity was the same as the mean songs average intensity and WN with increasing average intensity) and the number (intensity) of distractors (four levels). This analysis could only be carried out on data from five birds (three saline and two DSP-4) that completed the entire experiment in the same conditions. Because no effect of the treatment and no significant interaction of the treatment with other factors could be detected, data relative to these two groups of subjects were then pooled and re-analyzed 
by a two-way ANOVA with two repeated factors: the type of distractors and their intensity (see Fig. 4). This analysis confirmed the qualitative impression obtained by visual inspection of the data and showed the presence of a very significant effect of the distractors numbers/intensity $\left(F_{3,12}=49.358, p<0.0001\right)$ but no effect of the type of distractors $\left(F_{2,8}=2.994, p=0.1070\right)$ and no interaction between the two factors $\left(F_{6,24}=0.892\right.$, $p=0.5160$ ).

This analysis, therefore, confirmed that the ability to discriminate correctly the conspecific song segments decreases as a function of the amount of distractors superimposed to the targets or their intensity.

\section{Discussion}

The present study was designed to investigate some of the cognitive processes associated with song perception in adult male canaries. Song auditory processing presumably involves several complex cognitive abilities such as attention, memory, auditory discrimination and recognition. Some of these cognitive abilities were investigated in the present study through behavioral tasks implemented via an operant procedure. The results of the discrimination learning task indicate that adult male canaries display the perceptual abilities required to discriminate different song segments of a canary from different song segments of another conspecific bird with a high degree of accuracy. All song stimuli were recorded in Belgium but the testing took place in the USA, with birds bred locally in the USA. It is, therefore, clear that the birds used in this study had never experienced the stimulus vocalizations before. By performing this first behavioral task, adult male canaries also demonstrated their ability to learn arbitrary associations between the songs produced by two different canaries and different arbitrary objects such as perches.

We do not know on what acoustic basis the canaries were making the discrimination. On one hand, they could respond to some acoustic feature(s) distinguishing the songs produced by the two canaries. On the other hand, birds could have memorized the 10 song stimuli and sorted them appropriately. Based on a different behavioral procedure than what we employed in this study (counts of the numbers of calls emitted during or following exposure to a specific song play- back), Parisot et al. (2002) showed that male canaries are able to discriminate between sets of conspecific songs that do or do not contain what they called a "phrase A", that is a phrase containing abrupt frequency sweeps produced at high repetition rates. Phrase "A" are clearly preferred by females (Vallet and Kreutzer, 1995) and correspond to the sexually attractive fast frequency modulated syllables that were also identified in the repertoire of wild canaries in one island of the Madeira archipelago (Leitner et al., 2001). The wild canaries were found to increase the repetition rate of these syllables during the breeding season (Leitner et al., 2001). The stimuli used in the present experiments did not exhibit systematic variation in these phrases (see sonograms in Fig. 1B). It is, thus, probably not the case that variation in these syllables alone among the stimuli can explain the acoustic basis of the discriminations that were observed in the present study.

Discriminations between different songs (heard previously or not) were also demonstrated recently in zebra finches (Taeniopygia guttata) using behavioral responses to playback as the dependent measure but these experiments did not address the mechanisms underlying recognitions processes (Stripling et al., 2003). In European starlings, individual vocal recognition is also present and has been studied by operant conditioning procedures. The process involves the memorization of individually specific song types and the sequential ordering of song types within different bouts of an individual (Gentner and Hulse, 1998). Neither starlings nor song sparrows appear to classify song types according to voice characteristics (Beecher et al., 1994; Gentner et al., 2000). The present experiments, though they demonstrate song recognition, do not permit us to identify the acoustic proprieties by which canaries discriminate conspecific songs and additional experiments should be designed to directly investigate this question.

In the second phase of the experiment, the ability of the birds to maintain song discrimination when different distractors were added to mask partially the song stimuli was investigated. Correct responses were maintained when distractors were not too numerous or intense but then decreased as a function of the number or intensity of the distractors. These data indicate, therefore, that adult male canaries have the ability to discriminate and selectively attend to one ongoing sound that occurs simultaneously with one or 
more other sounds. As in humans and European starlings, domesticated canaries show that they also have the perceptual abilities to analyze the auditory scene, a phenomenon that clearly engages selective attentional processes (Bregman, 1990; Wisnieski and Hulse, 1997; Hulse, 2002). Birds were clearly able to identify birdsong signals in a noisy background despite the fact that all stimuli were delivered through a single speaker. Given that separate spatial locations for sounds facilitate the analysis of the auditory scene (Bregman, 1990), the abilities of the birds to discriminate and selectively attend to one song that occurs simultaneously with other sounds in a natural environment are likely underestimated in this study. The birds also demonstrated their ability to identify the stimuli when the distractors were constructed based on conspecific songs sharing a large number of acoustic features in common with the target stimulus. It is, however, quite surprising that the ability to maintain the discrimination was not differentially affected by the type of distractors (conspecific song versus white noises). Based on studies primarily performed in humans, one might have expected that distractors closely related to the stimuli would have a more drastic effect on information processing than distractors that are not related to the stimuli. Surprisingly, our results suggest that this is not the case in canaries. The two types of distractors did not have differential effects on the performances. This experiment did employ a relatively limited sample size $(n=7$ birds in total) due to the labor-intensive nature of the experimental procedures. In these conditions, no significance between distractor types could be detected but the probabillty associated with this conclusion was not very high $(p=0.1070)$ and one might hypothesize that with a larger number of subjects, and therefore, greater statistical power, the differences between these three conditions would become significant. However, the fact that, if anything, birds exposed to conspecific song as a distractor exhibited a better discrimination than birds exposed to white noise, runs counter to this hypothesis and this result is the opposite of what has been reported in humans (Bregman, 1990; see Fig. 4). If there is a trend towards a difference, it is, therefore, in the opposite direction from what would be expected based on human studies. The present data can, therefore, be taken as evidence suggesting that the mechanisms underlying these discrimination tasks are probably different in canaries and humans.
The present study was also carried out to provide preliminary information on the involvement of norepinephrine in the auditory processing of complex signals in songbirds. Although any conclusion on this aspect of the study can only be tentative due to the small number of subjects involved, it appears that DSP-4treated birds performed as well as control birds to discriminate accurately between the song exemplars of two different canaries. There was, however, a tendency for the treated group to learn the discrimination more slowly. This impairment could be explained by attentional deficits as suggested by the degree to which the treated birds failed to respond, a rate at least three times higher in the DSP-4-treated group than in the control one while there was no significant difference in the levels of correct and wrong responses between the two groups of birds. A previous study indicated that the same pharmacological treatment with DSP-4 does not affect the general motor activity in canaries (Appeltants et al., 2002b) and it is unlikely that the higher level of absence of response is due to a general debilitation of the subjects given that birds in both groups produced the same number of correct responses and learned the response at a similar pace. Taken together, the present data suggest that the noradrenergic innervation of the neuronal structures involved in song auditory processing participates to the attentional functions associated with song perception in adult male canaries. This hypothesis agrees with previous data indicating that central noradrenergic inputs modulate the sexual behavior of female canaries by affecting the auditory processing of the information contained in sexually stimulating songs (Appeltants et al., 2002b).

\section{Acknowledgements}

This research was supported by grants from the NINDS (NS 35467) to G.F.B. and J.B., and by grants from the Belgian FRFC (2.4555.01), the French Community of Belgium (ARC 99/04-241), and the University of Liège (Crédits spéciaux) to J.B. D.A. was research fellow with the FNRS.

\section{References}

Appeltants, D., Absil, P., Balthazart, J., Ball, G.F., 2000. Identification of the origin of catecholaminergic inputs to $\mathrm{HVc}$ in canaries 
by retrograde tract tracing combined with tyrosine hydroxylase immunocytochemistry. J. Chem. Neuroanat. 18, 117-133.

Appeltants, D., Ball, G.F., Balthazart, J., 2001. The distribution of tyrosine hydroxylase in the canary brain: demonstration of a specific and sexually dimorphic catecholaminergic innervation of the telencephalic song control nuclei. Cell Tissue Res. 304, 237-259.

Appeltants, D., Ball, G.F., Balthazart, J., 2002a. The origin of catecholaminergic inputs to the song control nucleus RA in canaries. Neuroreport 13, 649-653.

Appeltants, D., Del Negro, C., Balthazart, J., 2002b. Noradrenergic control of auditory information processing in female canaries. Behav. Brain Res. 133, 221-235.

Aston-Jones, G., Rajkowski, J., Kubiak, P., Tatania, A., 1994. Locus coeruleus neurons in monkey are selectively activated by attended cues in a vigilance task. J. Neurosci. 14, 4467-4480.

Ball, G.F., 1994. Neurochemical specializations associated with vocal learning and production in songbirds and budgerigars. Brain Behav. Evol. 44, 234-246.

Ball, G.F., Hulse, S.H., 1998. Birdsong Am. Psychol. 53, 37-58.

Balthazart, J., Libioulle, J.M., Sante, P., 1988. Stimulatory effects of the noradrenergic neurotoxin DSP4 on sexual behavior in male quail. Behav. Proc. 17, 27-44.

Barclay, S.R., Harding, C.F., Waterman, S.A., 1991. Correlations between catecholamine levels and sexual behavior in male zebra finches. Pharmacol. Biochem. Behav. 41, 195-201.

Barclay, S.R., Harding, C.F., Waterman, S.A., 1996. Central DSP-4 treatment decreases norepinephrine levels and courtship behavior in male zebra finches. Pharmacol. Biochem. Behav. 53, 213-220.

Beecher, M., Campbell, S.E., Burt, J., 1994. Song perception in the song sparrow: birds classify by song type but not by singer. Anim. Behav. 47, 1343-1351.

Bregman, A.S., 1990. Auditory Scene Analysis: The Perceptual Organization of Sound. MIT Press, Cambridge, MA.

Brenowitz, E.A., Margoliash, D., Nordeen, K.W., 1997. An introduction to birdsong and the avian song system. J. Neurobiol. 33, 495-500.

Eens, M., 1997. Understanding the complex song of the European starling: an integrated approach. Adv. Study Behav. 26, 355-434.

Fritschy, J.-M., Grzanna, R., 1989. Immunohistochemical analysis of the neurotoxic effects of DSP-4 identifies two populations of noradrenergic axon terminals. Neuroscience 30, 181-197.

Fritschy, J.-M., Grzanna, R., 1991. Selective effects of DSP4 on locus coeruleus axons - are there pharmacologically different types of noradrenergic axons in the CNS? Prog. Brain Res. 88, 257-268.

Fritschy, J.-M., Grzanna, R., 1992. Restoration of ascending noradrenergic projections by residual locus coeruleus neurons-compensatory response to neurotoxin induced cell death in the adult rat brain. J. Comp. Neurol. 321, 421-441.

Gentner, T.Q., Hulse, S.H., 1998. Perceptual mechanisms for individual vocal recognition in European starling, Sturnus vulgaris. Anim. Behav. 56, 579-594.

Gentner, T.Q., Hulse, S.H., Bentley, G.E., Ball, G.F., 2000. Individual vocal recognition and the effect of partial lesions to $\mathrm{HVc}$ on discrimination, learning, and categorization of conspecific song in adult songbirds. J. Neurobiol. 42, 117-133.

Hallman, H., Sundstrom, E., Jonsson, G., 1984. Effects of the noradrenaline neurotoxin DSP4 on monoamine neurons and their transmitter turnover in the rat CNS. J. Neural Transm. 60, 89102.

Hulse, S.H., 2002. Auditory scene analysis in animal communication. Adv. Study Behav. 31, 163-200.

Hulse, S.H., MacDougall-Shackleton, S.A., Wisniewski, A.B., 1997. Auditory scene analysis by songbirds: stream segregation of birdsong by European starling (Sturnus vulgaris). J. Comp. Psychol. 111, 3-13.

Jaim-Etcheverry, G., Zieher, L., 1980. DSP4: a novel compound with neurotoxic effects on noradrenergic neurons of adult and developing rats. Brain Res. 188, 513-523.

Kroodsma, D.E., Byers, B.E., 1991. The functions of bird song. Am. Zool. 31, 318-328.

Leitner, S., Voigt, C., Gahr, M., 2001. Seasonal changes in the song pattern of the non-domesticated island canary (Serinus canaria): a field study. Behaviour 138, 885-904.

Leonardo, A., Konishi, M., 1999. Decrystallisation of adult birdsong by perturbation of auditory feedback. Nature 399, 466-470.

Lind, H., Dabelsteen, T., McGregor, P.K., 1996. Female great tits can identify mates by song. Anim. Behav. 52, 667-671.

Lyons, W.E., Fritschy, J.M., Grzanna, R., 1989. The noradrenergic neurotoxin DSP-4 eliminates the coeruleospinal projection but spares projections of the A5 and A7 groups to the ventral horn of the rat spinal cord. J. Neurosci. 9, 1481-1489.

Marler, P., 1997. Three models of song learning: evidence from behavior. J. Neurobiol. 33, 501-516.

Nottebohm, F., Stokes, T.M., Leonard, C.M., 1976. Central control of song in the canary, Serinus canarius. J. Comp. Neurol. 165, 457-486.

Parisot, M., Vallet, E., Nagle, L., Kreutzer, M., 2002. Male canaries discriminate among songs: call rate is a reliable measure. Behaviour 139, 55-63.

Peter, S.S., Searcy, W.A., Marler, P., 1980. Species song discrimination in choice experiments with territorial male swamp and song sparrows. Anim. Behav. 28, 393-404.

Reiner, A., Perkel, D.J., Bruce, L.L., Butler, A.B., Csillag, A., Kuenzel, W., Medina, L., Paxinos, G., Shimizu, T., Striedter, G., Wild, M., Ball, G.F., Durand, S., Güntürkün, O., Lee, D.W., Mello, C.V., Powers, A., White, S.A., Hough, G., Kubikova, L., Smulders, T.V., Wada, K., Dugas-Ford, J., Husband, S., Yamamoto, K., Yu, J., Siang, C., Jarvis, E.D., 2004. Revised nomenclature for avian telencephalon and some related brainstem nuclei. J. Comp. Neurol. 473, 377-414.

Riters, L.V., Eens, M., Pinxten, R., Ball, G.F., 2002. Seasonal changes in the densities of alpha2-noradrenergic receptors are inversely related to changes in testosterone and the volumes of song control nuclei in male European starlings. J. Comp. Neurol. 444, 63-74.

Sara, S.J., 1985. The locus coeruleus and cognitive function: attempts to relate noradrenergic enhancement of signal/noise in the brain to behavior. Physiol. Psychol. 13, 151-162.

Stripling, R., Milewski, L., Kruse, A.A., Clayton, D.F., 2003. Rapidly learned song-discrimination without behavioral reinforcement in adult male zebra finches (Taeniopygia guttata). Neurobiol. Learn. Mem. 79, 41-50.

Turetsky, B.I., Fein, G., 2002. Alpha2-noradrenergic effects on ERP and behavioral indices of auditory information processing. Psychophysiology 39, 147-157. 
Vallet, E., Kreutzer, M., 1995. Female canaries are sexually responsive to special song phrases. Anim. Behav. 49, 16031610.

Wisnieski, A.B., Hulse, S.H., 1997. Auditory scene analysis in European starling (Sturnus vulgaris): discrimination of song segments, their segregation from multiple and reversed conspecific songs, and evidence for conspecific song categorization. J. Comp. Psychol. 111, 337-350.
Wood, N., Cowan, N., 1985. The cocktail party phenomenon revisited: how frequent attention shifts to one's name in an irrelevant auditory channel. J. Exp. Psychol. 21, 255-260.

Woodward, D.J., Moises, H.C., Waterhouse, B.D., Yeh, H.H., Cheun, J.E., 1991. Modulation actions of norepinephrine on neural circuits. Adv. Exp. Biol. 287, 193-208.

Zeigler, H.P., Marler, P., 2004. Behavioral neurobiology of birdsong. Ann. N. Y. Acad. Sci. 1016, 788. 